NASA Technical Memorandum 88906

\title{
Representation of the Vaporization Behavior of Turbulent Polydisperse Sprays by “Equivalent" Monodisperse Sprays
}

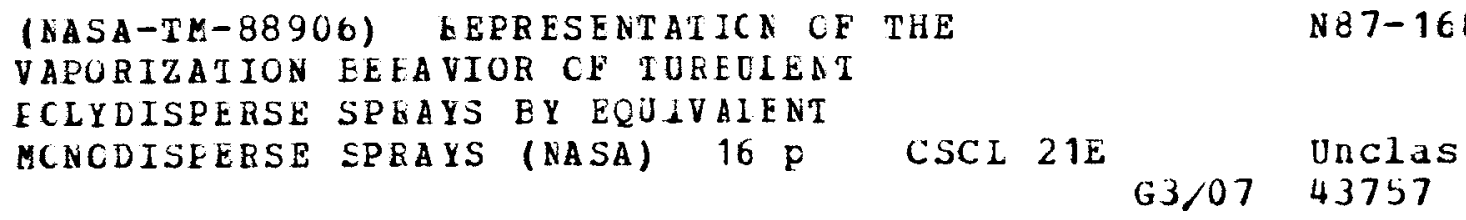

S.K. Aggarwal

Lewis Research Center

Cleveland, Ohio

and

J.S. Shuen

Sverdrup Technology, Inc.

Lewis Research Center

Cleveland, Ohio

December 1986 
REPRESENTATION OF THE VAPORIZATION BEHAVIOR OF TURBULENT POLYDISPERSE SPRAYS

BY "EQUIVALENT" MONODISPERSE SPRAYS

\author{
S.K. Aggarwa $]^{*}$ \\ National Aeronautics and Space Administration \\ Lewis Research Center \\ cleveland, Ohio 44135 \\ and \\ J.S. Shuen \\ Sverdrup Technology, Inc. \\ Lewis Research Center \\ Cleveland, Ohio 44135
}

\title{
SUMMARY
}

Concept of using an equivalent monodisperse spray to represent the vaporization behavior of polydisperse sprays has been examined by numerically solving two turbulent vaporizing sprays. One involves the injection of freon-li in a still environment, whereas the other is a methanol spray in a still but hot environment. The use of three different mean sizes, namely, Sauter mean diameter, volume median diameter, and surface-area mean diameter, has been investigated. Results indicate a good degree of correlation between the polydisperse spray and its equivalent monodisperse sprays represented by the volume median diameter and the Sauter mean diameter, the former giving silghtly better results. The surface-area mean diameter does not provide as good a correlation as the other two mean diameters.

\section{INTRODUCTION}

This work is aimed at examining the concept of an "equivalent" monodisperse spray with some suitable mean drop size. Purpose is to explore if an "equivalent" monodisperse spray can adequately represent the behavior of a given polydisperse spray, and if it can, what is the droplet size of this equivalent spray. The work is important because the adequate initial conditions are currently not available for spray, computations, and because the numerical efforts involved in solving realistic polydisperse sprays could be enormous.

Most researchers have employed the Sauter mean diameter to represent a polydisperse spray. There is no evidence, however, to establish that this diameter is the most suitable diameter for simulating the behavior of polydisperse sprays. There have been some studies (refs. 1 to 4 ) which have attempted to find the most representative diameter. Dickinson and Marshall (ref. 1) concluded that for diffusion-controlled vaporization, no mean diameter can adequately represent the vaporization characteristics of polydisperse sprays. Alkidas (ref. 2) conducted an analytical study on steady state vaporization

*Summer Faculty Fellow. Present address: Dept. of Mechanical Engineering, University of Illinois, Chicago, Illinois 60680. 
and concluded that the Sauter mean diameter best correlates the overall vaporization behavior of sprays of different initial size distributions for both diffusion-controlled and radiation-controlled vaporization. A study by Aggarwal and Sirignano (ref. 3) indicated that the ignition characteristics of polydisperse sprays are best represented by the surface-area mean diameter and not by the Sauter mean diameter (SMD). A more recent study by Aggarwal (ref. 4) concluded that the flame characteristics of polydisperse sprays are best simulated by the SMD, although the surface-area mean diameter is still the more appropriate one for representing the ignition behavior. Yet another investigation (ref. 5) indicated that the volume median diameier is a more suitable diameter. Clearly there is no general consensus on the most optimum mean diameter. Moreover, these studies have analyzed idealized situations.

The present study is directed toward examining the above issue by considering a more realistic situation of a vaporizing turbulent spray for which the initial droplet size distribution is obtained experimentally. Two cases are considered. First is an evaporating Freon-11 spray produced by an airatomizing injector in a still environment. Experimental data for initial conditions are available for this case. Second is an evaporating methanol spray which is also assumed to be produced by an air-atomizing injector but in a hot environment. Since no experimental data is avallable for this case, the initial conditions are assumed to be the same as given in the first case. For both the cases, results are obtained for the polydisperse spray and compared with those for three equivalent monodisperse sprays represented respectively by the Sauter mean diameter $\left(d_{32}\right)$, the surface-area-mean diameter $\left(d_{20}\right)$, and the volume median diameter $\left(\mathrm{d}_{0.5 \mathrm{v}}\right)$.

\section{Brief Description of the Physical Model}

Major assumptions for the continuous phase are: axisymmetric and steady flow, boundary layer approximations apply, equal exchange coefficients of all species and heat, buoyancy only affects mean flow, and negligible effects of mean kinetic energy and radiation. The analysis employs Favre-averaged governing equations and a $k-\varepsilon-g$ turbulent model for the gas-phase, since this approach provided good predictions of the structures of variable density single-phase jets, as well as evaporating and combusting sprays, during past work (refs. 6 and 7 ). Scalar properties (such as density and temperature) are obtained by using conserved scalar approach in conjunction wth state relationships constructed by adiabatic mixing calculations.

The liquid phase is treated by solving Lagrangian equations of motion and transport for trajectories of a statistically-significant sample of individual droplets and then computing source terms for mass, momentum and energy due to droplets which appear in the governing equations for the gas phase. This involves dividing the droplets into $n$ groups (defined by position, diameter, and velocity) at the initial condition, and then computing their subsequent life-histories in the flow. The stochastic-separated-flow formulation of references 6 and 7 is adopted for droplet calculations. In this approach, the droplets are assumed to interact with a random distribution of turbulent eddies, providing simultaneously for droplet dispersion by turbulence and effects of turbulent fluctuations on interphase transport. The scales and the properties of each eddy and the time of interaction of a droplet with a particular eddy are found using the methods described by Shuen et.al. (refs. 6 and 7). 
The assumptions for the droplet transport calculations as well as the complete formulation of the separated-flow model are given in detail in references 6 and 7 , and, therefore, will not be repeated here.

\section{Definition of Mean Diameters} relation

Various mean diameters for a polydisperse spray are defined by the

$$
x_{i j}=\left\{\int_{0}^{\infty} x^{i} d n \int_{0}^{\infty} x^{j} d n\right\}^{\frac{1}{1-j}}
$$

where dn represents the number of droplets with diameter between $x$ and $x+d x$.

For the Sauter mean diameter $i=3$ and $j=2$, whereas for the surfacearea mean diameter $i=2$ and $j=0$.

Normalized cumulative volume for the liquid phase is defined as

$$
c_{v}(x)=\int_{0}^{x} x^{3} d n / \int_{0}^{\infty} x^{3} d n
$$

and the volume median diameter is defined as the value of upper limit in the above integral corresponding to $c_{v}=0.5$.

\section{Initial Conditions for the Monodisperse Sprays}

Using the experimental size distribution, the values of $d_{32}$ and $d_{20}$ were calculated as a function of jet radial location. The result indicated that $d_{32}$ and $d_{20}$ are almost uniform in the radial direction initially. Thus a single droplet size is sufficient for specifying the initial liquid mass distribution.

The volume median diameter can be calculated by using equation (2), where the integral is computed numerically by using the experimental size distribution. The calculated values for $d_{20}, d_{32}$, and $d_{0.5 v}$ for the experimental size distribution are $48.4,59.8$, and $65.0 \mu \mathrm{m}$, respectively. For the monodisperse sprays, the droplet velocity distribution is obtained by using the assumption that the velocity distribution for a given drop size is the same as the experimental velocity distribution for that size. For example, for mono. disperse spray with $d_{32}(=59.8 \mu \mathrm{m})$, the initial velocity distribution corresponds to the experiment values for droplet size of $59.8 \mu \mathrm{m}$. A slightly better velocity distribution may be obtained from the total liquid-momentum flux considerations, i.e., by equating the total momentum flux of the monodis. perse spray to that of the polydisperse spray. However, the differences between the two distributions were found to be small. 


\section{Results for the Freon-11 Spray}

For the evaporating freon-11 spray, the initial conditions for two-phase calculations are taken from the experimental data of reference 6 at $x / D=50$. Results for the polydisperse and three equivalent monodisperse sprays represented by $\mathrm{d}_{32}, \mathrm{~d}_{20}$, and $\mathrm{d}_{0.5 \mathrm{v}}$ are presented in figures 1 to 3 . Variation of freon vapor mass fraction in the jet is given in figure 1 . Agreement between the four cases is excellent, both in terms of the axial and radial variations. The profiles of gas temperature in the axial and radial directions are also almost identical for the four cases (not shown). Such an excellent agreement may be somewhat misleading because the freon vapor mass fraction at the initial station $(x / 0=50)$ is relatively high. Its variation is then controlled by the fluid-dynamical and mixing processes rather by the liquid-phase processes. Figures 2 and 3 are perhaps more representative of the differences between the polydisperse and the equivalent monodisperse sprays. Radial profiles of total freon mass fraction at $x / D=400$ and 500 are shown in figure 2 . Differences, which are relatively large at $x / D=500$ are somewhat exaggerated because 80 percent of liquid mass is evaporated and only very large droplets are remaining at this location. Thus, figure 2(b), which indicates a good degree of correlation between the polydisperse spray and its equivalent monodisperse sprays, provides a better representation of the differences in most of the jet. Radial variation of liquid flux at two axial locations is given in figure 3. Again, figure 3(b), which provides a better representation of the differences than figure $3(a)$, shows that the vaporization behavior of polydisperse sprays can be reasonably represented by the equivalent monodisperse sprays. Amongst the three monodisperse sprays, the one with the volume median diameter seems to provide the closest predictions to the polydisperse spray, whereas the $d_{20}$ sprays shows the largest differences. Variation of liquid flux along the jet axis, given in table $I$, demonstrates similar degree of correlation between polydisperse and three monodisperse sprays, with $d_{0.5 v}$ and d20 sprays showing, respectively, the best and the worst agreement with the polydisperse spray. At $x / D=70$, d0.5v and $d 32$ sprays overpredict the centerline liquid flux. This is perhaps the fluid-dynamic effect, as the jet interior is relatively cold and the vaporization rate is small. Smaller droplets tend to move away from the centerline whereby reducing the liquid mass flux there for the polydisperse case. For $x / 0$ between 100 and 400 , the do.5v spray continues to overpredict the centerline liquid flux, which is now due to the vaporization effect, i.e., the smaller droplets in the polydisperse spray are vaporizing faster. For $x / 0$ greater than 500 , the liquid flux is higher for the polydisperse case because only the large droplets are remaining. However, the differences are not important there, as most of the liquid mass has already vaporized.

Differences between the polydisperse and $d_{20}$ sprays are small initially. Further downstream, $x / D$ between 150 and 250 , the $d 20$ spray overpredicts the centerline liquid flux due to the faster vaporization of smaller droplets in the polydisperse case. For $x / D$ greater than 250 , liquid flux is higher for the polydisperse spray for the same reason as mentioned earlier. Perhaps, the radial distribution of liquid flux, as given in table $I(b)$ at $x / D=150$, provides a better representation of the differences between the four cases. In the inner region, the monodisperse sprays generally overpredict, whereas in the outer region they underpredict the liquid flux as compared to the polydisperse case. The differences are due to the vaporization effect and the radial distribution of gas temperature. The inner region is 
relatively cold, thus, only the smaller droplets in the polydisperse spray experience significant vaporization. In the outer region, the vaporization rate is higher for the monodisperse sprays as compared to the polydisperse spray since the gas temperature is relatively higher.

Total freon mass fraction values at the centerline for the four cases are shown in table $I(a)$. Obviously the differences between polydisperse and monodisperse sprays are much smaller as compared to those in the liquid flux comparison.

\section{CONCLUDING REMARK}

The major conclusion from the above results is that the vaporization behavior of polydisperse sprays can be represented by the equivalent monodisperse sprays. There is a reasonably good correlation, both in terms of gasphase as well as liquid-phase properties, between the polydisperse and three monodisperse sprays. Moreover, the use of equivalent monodisperse spray reduces the computational effort by a factor of six. For the present results, the use of volume median diameter best represents the polydisperșe spray behavior, although the Sauter mean diameter and the surface-area-mean diameter also provide a reasonably good correlation to the polydisperse spray. It should be noted, however, that the freon-11 spray, due to its fast vaporization characteristics and due to high value of initial fuel vapor concentration, may not be a good test case for examining the degree of correlation between the polydisperse spray and its equivalent monodisperse sprays. This issue is pursued further by using a methanol spray, as discussed in the next section.

\section{Methanol Spray Results}

Results are now presented for a vaporizing turbulent methanol spray. The purpose is to further examine the degree of correlation between the polydisperse spray and its equivalent monodisperse sprays. The physical model is essentially the same as that for the freon-11 case, except that a methanol spray in hot still surroundings, which is a temperature of $800^{\circ} \mathrm{K}$, is considered. Initial distribution of gas-phase properties is assumed to be the same as that for the freon-11 spray. Initial droplet size and velocity distributions are also assumed to be the same as that for the freon spray. Note that no other experimental data is avallable in the literature. Another reason for using the same initial conditions as much as possible is to alter only the vaporization characteristics of the spray without changing its fluid-dynamical characteristics. Methodology for calculating droplet size-history and trajectory is identical to the one employed in reference 7. Transport and thermo. dynamic properties as well as the equations of states (for calculating gas temperature and density) are also computed by following the procedure of reference 7. Direct droplet interaction is neglected and the thin skin approximation (ref. 7) is employed. Further details are given in the above reference.

Results are again obtained for the polydisperse case and compared with those for the three monodisperse sprays. Methanol vapor distribution in the jet for all four cases is shown in figure 4 . The differences in the radial distribution of methanol vapor are negligible. In the axial direction, the 
agreement between the polydisperse, $d_{32}$, and $d_{0.5 v}$ sprays is quite reasonable. However, the $\mathrm{d}_{20}$ spray indicates significant departure from the polydisperse spray, the maximum difference being 35 percent as compared to 10 percent for the $d_{32}$ and $d_{0.5 v}$ sprays. It is also interesting to note that the differences between polydisperse and monodisperse sprays are now more significant as compared to the freon case. Compare figures 1(a) and 4(a). This is due to the large amount of initial fuel vapor in the freon case; the methanol vapor mass fraction at the initial location is zero. Consequently, the differences in the vaporization behavior of polydisperse and monodisperse sprays are better highlighted with the methanol spray. More interesting observation is that even for the methanol case, the results for $d_{32}$ and $d_{0.5 v}$ sprays are quite encouraging.

Radial variation of total methanol mass fraction and of liquid flux are shown in figures 5 and 6 , respectively.

Radial distribution of liquid flux at two axial locations is given in figure 5. At $x / D=150$, the $d_{32}$ predictions seem to be the closest to the polydisperse results. Except near the jet edge, the liquid flux values are higher for the $d_{32}$ and $d_{0.5 v}$ sprays because the small droplets in the polydisperse spray are vaporizing faster. Note that, unlike the freon case, the interior of the jet is hot and the vaporization there is significant in the present case. Moreover, the effect of gas-phase convection on droplet vaporization is the largest at the jet axis. As a result, the liquid flux at the axis is lower as compared to the values in the jet interior. The liquid flux values for the $d_{20}$ spray are underpredicted, which indicates faster vaporization for this case as compared to the polydisperse case. It is also noteworthy that the actual differences between the polydisperse and the monodis. perse sprays are smaller than those indicated in figure 5(a). This is because the liquid flux has been normalized by the center-line value, which is smaller for the $d_{0.5 \mathrm{v}}$ and $d_{32}$ sprays but higher for the $d_{20}$ spray as compared to the polydisperse case. The center-line liquid flux is given in table II.

The radial distributions of methanol liquid flux at $x / 0=300$ (fig. $5(\mathrm{~b})$ ) is remarkedly different from those at $x / D=150$. Results for all three monodisperse sprays are now in agreement with each other, but are consistently underpredicted as compared to the polydisperse case. The underprediction is due to the fact that most of the liquid (more than 80 percent) has already vaporized at this location and only a few large droplets in the polydisperse spray are remaining. Thus, the results in figure 5(a) along with table II are more representative of the differences between the four sprays as compared to those in figure $5(b)$.

Figure 6 shows the radial variation of total methanol mass fraction. Obviously, the agreement is much better here as compared to that in figure 5 . Table III, which gives the axial variation of total liquid and vapor mass flow rate, provides a global comparison of the vaporization behavior of polydisperse spray with its equivalent monodisperse sprays. Again, the degree of correlation between the polydisperse and $d_{0.5 \mathrm{v}}$ sprays, and between the polydisperse and $\mathrm{d} 32$ sprays is quite acceptable up to $x / 0=250$. It deterforates further downstream but is unimportant as much of the liquid has already vaporized. Another interesting observation emerges from the comparison of figures 3 and 5. The differences between the polydisperse and monodisperse sprays are 
relatively larger for the methanol case and are more typical of the degree of correlation between the vaporization behavior of polydisperse spray and its equivalent monodisperse spray. The methanol results are nevertheless encouraging, specially for the $d_{0.5 v}$ and $d_{32}$ sprays.

\section{CONCLUSIONS}

Structure of evaporating turbulent sprays is numerically computed and the use of "equivalent" monodisperse spray for simulating the vaporization behavior of realistic polydisperse sprays is investigated. The physical and numerical models are the same as in reference 6 . Three mean diameters which are examined are the Sauter mean diameter, volume median diameter, and surface-area mean diameters. Results are obtained for a freon-11 spray in a still environment and for a methanol spray also in a still but hot environment. For both cases, the results for the polydisperse spray are compared with those for its equivalent monodisperse sprays. Major conclusions are:

(1) For the freon-11 case, the degree of correlation between the polydisperse and equivalent monodisperse sprays is quite good. Amongst the three mean diameters, the volume median diameter and the surface-area mean diameter provide respectively the best and the worst representation of polydisperse spray behavior. The results for the Sauter mean diameter are quite close to those for the volume median diameter.

(2) For the methanol case, the correlation between the equivalent monodisperse and polydisperse sprays is not quite as good as for the previous case but is still acceptable. Again, the volume median diameter best simulates the vaporization behavior of polydisperse spray.

(3) The methanol spray results are perhaps more typical of a turbulent vaporizing spray than those for the freon 11 because of the high initial vapor concentration in the latter.

(4) The use of a suitable mean diameter is also encouraging due to the reduction in computational efforts by a factor of six. This will become more of an issue as advanced vaporization models (ref. 8) are employed or if the combustion situation is considered.

(5) The general conclusion is that the use of a suitable defined monodisperse spray for representing a realistic polydisperse spray is quite encouraging. The degree of correlation in the more interesting region of spray, where more than 80 percent of the liquid vaporizes, is acceptable to quite good. It can perhaps be improved further by employing two mean diameters.

\section{REFERENCES}

1. Dickinson, D.R.; and Marshall, W.R.: The Rates of Evaporation of Sprays. AIChE J., vol. 14, no. 4, July 1968, pp. 541-552.

2. Alkidas, A.C.: The Influence of Size-Distribution Parameters on the Evaporation of Polydisperse Dilute Sprays. Int. J. Heat Mass Trans., vol. 24, no. 12, Dec. 1981, pp. 1913-1923. 
3. Aggarwa 1, S.K.; and Sirignano, W.A.: Ignition of Polydisperse Sprays; Importance of $\mathrm{D}_{20}$. Combust. Sci. Technol., vol. 46, nos. 3-6, 1986, pp. 289-300.

4. Aggarwal, S.K.: Unsteady Flame Propagation in a Polydisperse SingleComponent Fuel Spray. AIAA Paper 86-1525, June 1986.

5. Ingebo, R.D.: Characterization of Simulated Small Droplet Fuel Sprays. AIAA Paper 86-1725, June 1986.

6. Solomon, A.S.P., et al.: A Theoretical and Experimental Study of Turbulent Evaporating Sprays. NASA CR-174760, 1984.

7. Shuen, J.S.; Solomon, A.S.P.; and Faeth, G.M.: The Structure of Dilute Combusting Sprays. NASA CR-174838, 1985.

8. Aggarwa 1, S.K.; Tong, A.Y.; and Sirignano, W.A.: A Comparison of Vaporization Models in Spray Calculations. AIAA j., vol. 22, no. 10, Oct. 1984, pp. 1448-1457. 
TABLE I

(a) Variation of liquid flux and total freon mass fraction along the jet axis

\begin{tabular}{|c|c|c|c|c|c|c|c|c|}
\hline \multirow[t]{2}{*}{$x / 0$} & \multicolumn{3}{|c|}{$\begin{array}{c}\text { Liquid flux at } \\
\text { the jet axis } \\
\text { (normalized by the value at }\end{array}$} & \multirow{2}{*}{$\frac{x / 0=50)}{d_{20}}$} & \multicolumn{4}{|c|}{$\begin{array}{l}\text { Total freon mass } \\
\text { fraction at the jet axis }\end{array}$} \\
\hline & $\begin{array}{l}\text { Poly- } \\
\text { disperse }\end{array}$ & $d_{0.5 \mathrm{v}}$ & $d_{32}$ & & $\begin{array}{l}\text { Poly- } \\
\text { disperse }\end{array}$ & $d_{0.5 v}$ & $d_{32}$ & $d_{20}$ \\
\hline $\begin{array}{r}50 \\
70 \\
100 \\
150 \\
250 \\
400 \\
500 \\
600\end{array}$ & $\begin{array}{l}1.0 \\
.560 \\
.328 \\
.194 \\
.102 \\
.032 \\
.012 \\
.005\end{array}$ & $\begin{array}{l}1.0 \\
.630 \\
.330 \\
.206 \\
.111 \\
.034 \\
.009 \\
.003\end{array}$ & $\begin{array}{l}1.0 \\
.630 \\
.318 \\
.160 \\
.150 \\
.033 \\
.009 \\
.001\end{array}$ & $\begin{array}{l}1.0 \\
.560 \\
.314 \\
.287 \\
.141 \\
.019 \\
.001 \\
0\end{array}$ & $\begin{array}{r}0.526 \\
.385 \\
.287 \\
.216 \\
.165 \\
.119 \\
.095 \\
.077\end{array}$ & $\begin{array}{r}0.526 \\
.390 \\
.285 \\
.214 \\
.167 \\
.124 \\
.095 \\
.078\end{array}$ & $\begin{array}{r}0.526 \\
.390 \\
.285 \\
.204 \\
.191 \\
.126 \\
.096 \\
.075\end{array}$ & $\begin{array}{l}0.526 \\
.386 \\
.289 \\
.250 \\
.203 \\
.124 \\
.09 \\
.073\end{array}$ \\
\hline
\end{tabular}

(b) Radial variation of liquid

flux at $x / 0=150$

\begin{tabular}{|c|c|c|c|c|}
\hline$r / x$ & Polydisperse & $d_{20}$ & $d_{0.5 v}$ & $d_{32}$ \\
\hline 0.013 & 0.194 & 0.287 & 0.206 & 0.160 \\
.044 & .192 & .218 & .227 & .27 \\
.082 & .10 & .12 & .12 & .09 \\
.12 & .03 & .014 & .034 & .02 \\
.17 & .003 & .001 & .001 & .001 \\
\hline
\end{tabular}

TABLE II. - LIQUIO FLUX AT THE CENTERLINE, NORMALIZED BY THE VALUE AT $X / 0=50$

\begin{tabular}{|l|c|c|c|c|}
\hline$x / 0$ & Polydisperse & $d_{0.5 v}$ & $d_{32}$ & $d_{20}$ \\
\hline 50 & 1.0 & 1.0 & 1.0 & 1.0 \\
70 & .539 & .562 & .557 & .522 \\
100 & .295 & .275 & .245 & .273 \\
150 & .759 & .133 & .137 & .225 \\
200 & .101 & .12 & .116 & .119 \\
250 & .056 & .086 & .078 & .045 \\
300 & .029 & .038 & .026 & .006 \\
350 & .015 & .012 & .005 & .0003 \\
\hline
\end{tabular}


TABLE III. - COMPARISON OF TOTAL LIQUIO

MASS FLOW RATE AND TOTAL VAPOR MASS

FLOW RATE FOR THE FOUR SPRAYS

(a) Total liquid mass flow rate

\begin{tabular}{|c|c|c|c|c|}
\hline$x / 0$ & $\begin{array}{c}\text { Polydis- } \\
\text { perse }\end{array}$ & $d_{32}$ & $d_{0.5 \mathrm{v}}$ & $\mathrm{d}_{20}$ \\
\hline \multicolumn{5}{|c|}{ Total liquid mass flow rate, $\mathrm{kg} / \mathrm{sec}$} \\
\hline 50 & $2.39 \times 10-4$ & $2.39 \times 10-4$ & $2.39 \times 10-4$ & $2.39 \times 10-4$ \\
70 & 2.09 & 2.04 & 2.12 & 1.89 \\
100 & 1.77 & 1.74 & 1.83 & 1.5 \\
150 & 1.34 & 1.27 & 1.38 & .98 \\
200 & .98 & .86 & 1.0 & .58 \\
250 & .70 & .52 & .66 & .27 \\
300 & .47 & .26 & .38 & .07 \\
350 & .30 & .09 & .17 & .004 \\
\hline
\end{tabular}

(b) Total vapor mass flow rate

\begin{tabular}{|r|l|l|l|l|}
\hline$x / 0$ & $\begin{array}{l}\text { Polydis- } \\
\text { perse }\end{array}$ & \multicolumn{1}{|c|}{$d_{32}$} & $d_{0.5 \mathrm{v}}$ & $\mathrm{d}_{20}$ \\
\hline \multicolumn{5}{|c|}{ otal vapor mass flow rate, $\mathrm{kg} / \mathrm{sec}$} \\
\hline 50 & 0 & 0 & 0 & 0 \\
70 & $.25 \times 10-4$ & $.22 \times 10-4$ & $.21 \times 10-4$ & $.31 \times 10-4$ \\
100 & .56 & .51 & .49 & .69 \\
150 & .99 & .99 & 0.94 & 1.21 \\
200 & 1.34 & 1.39 & 1.33 & 1.61 \\
250 & 1.62 & 1.73 & 1.67 & 1.92 \\
300 & 1.85 & 1.99 & 1.95 & 2.1 \\
350 & 2.01 & 2.15 & 2.15 & 2.15 \\
\hline
\end{tabular}




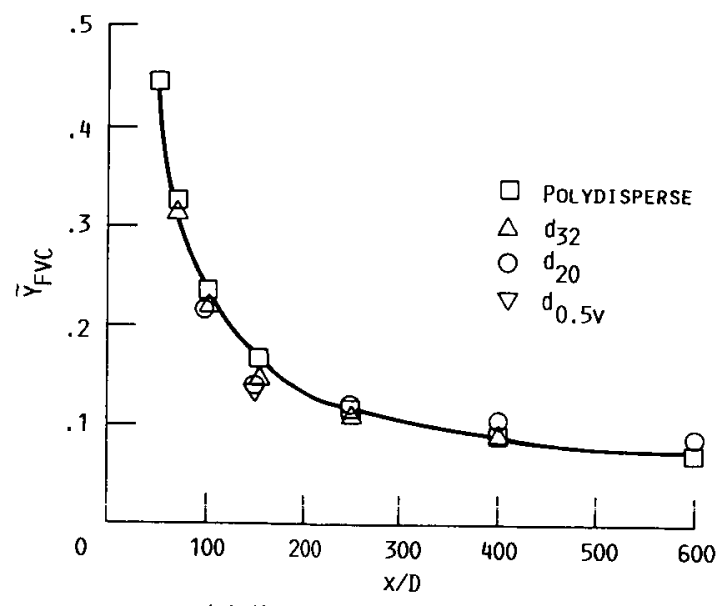

(a) VARIATION ALONG THE SPRAY aXIS.

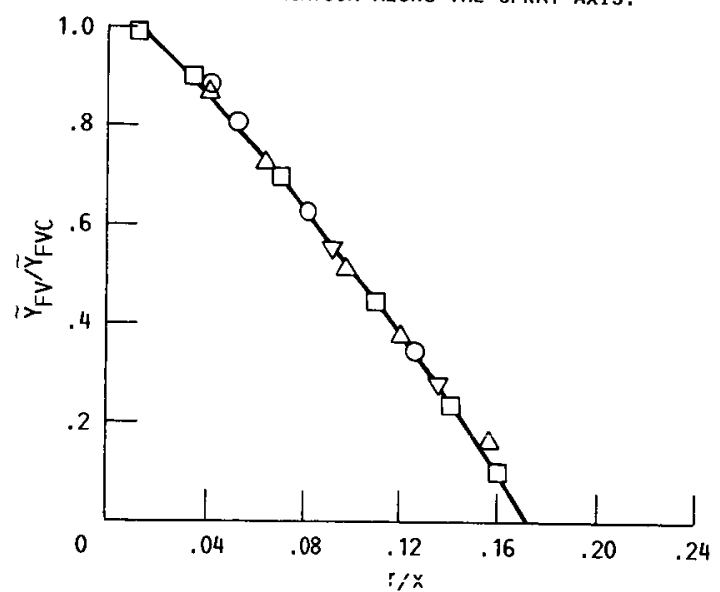

(B) RADIAL VARIATION AT $X / D=500$.

FIGURE 1.- VARIATION OF FREON VAPOR MASS FRACTION IN THE TURBULENT EVAPORATING SPRAY FOR THE POLY-
DISPERSE AND THREE EQUIVALENT MONODISPERSE SPRAYS 


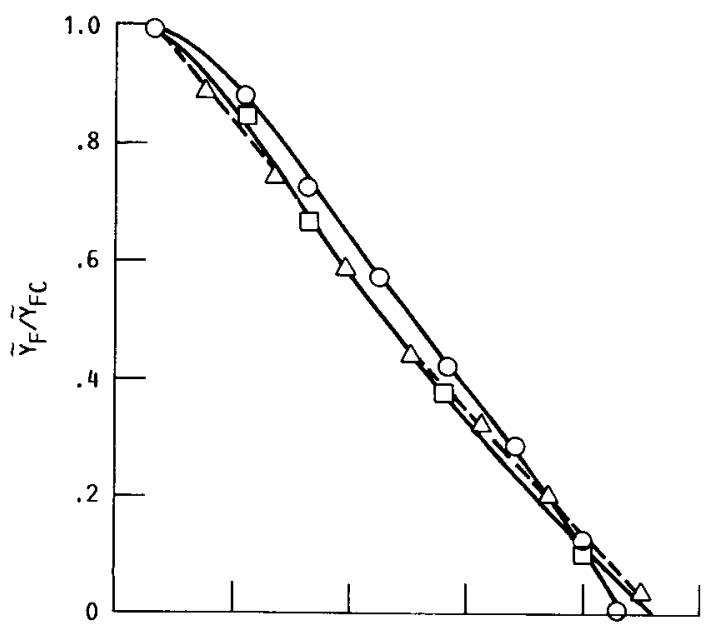

(A) $x / D=500$.

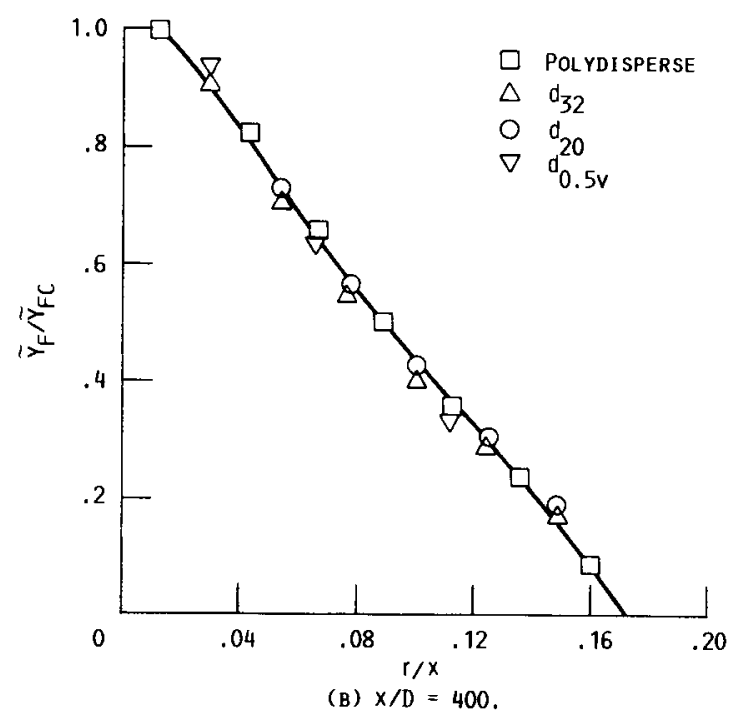

FIGURE 2. - RADIAL VARIATION OF TOTAL FREON-11 MASS FRACTION FOR THE POLYDISPERSE AND EQUIVALENT MONODISPERSE SPRAYS. 

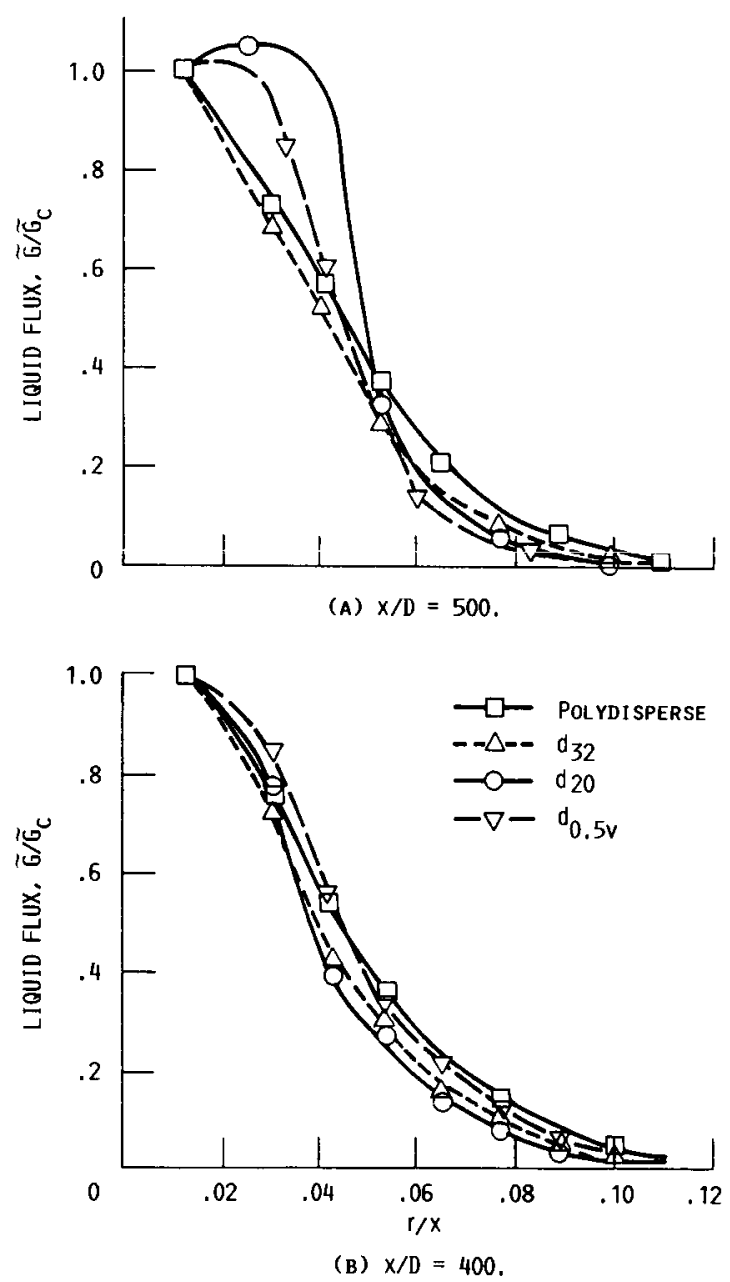

FIgURE 3.- RADIAL VARIATION OF MEAN LIOUID FREON FLUX FOR THE POLYDISPERSE AND EQUIVALENT MONODISPERSE SPRAYS. 

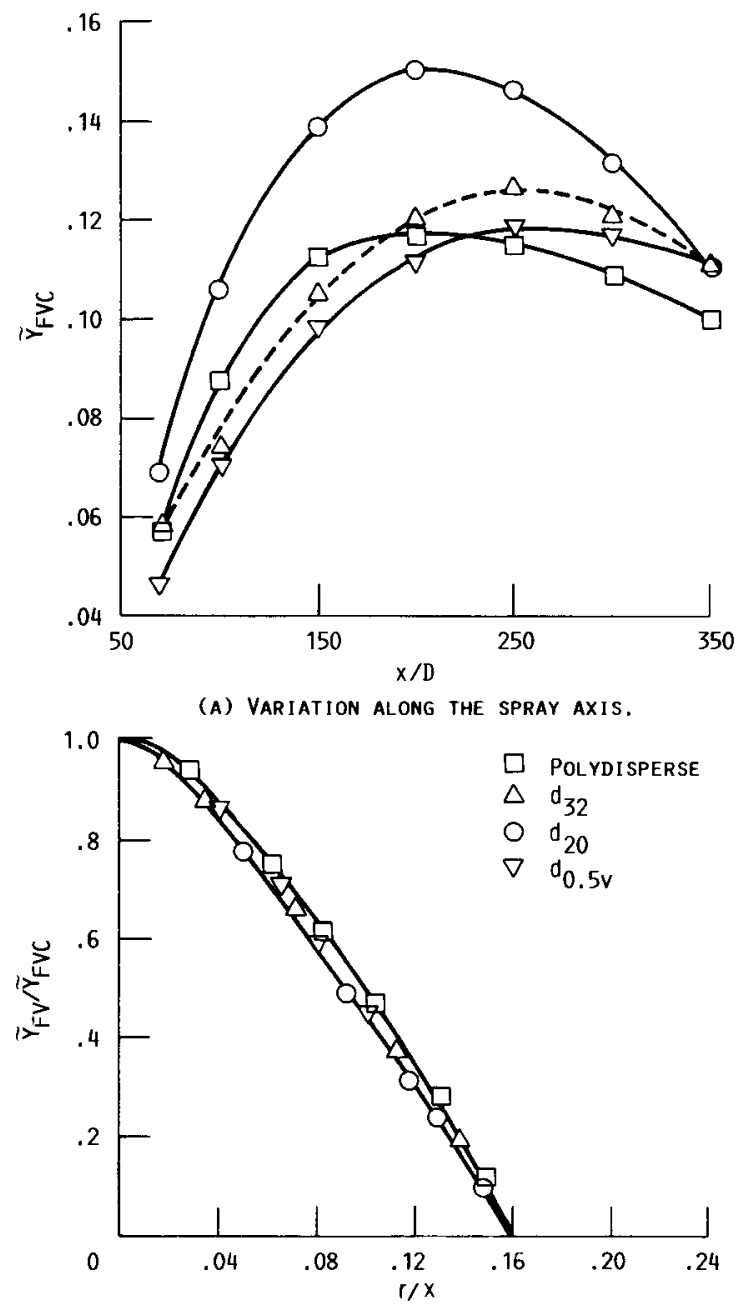

(B) RADIAL VARIATION AT $X / D=250$.

FIGURE 4.- VARIATION OF METHANOL VAPOR MASS FRACTION IN THE TURBULENT EVAPORATING SPRAY FOR THE POL YDISPERSE AND THREE EQUIVALENT MONODISPERSE
SPRAYS. SPRAYS. 

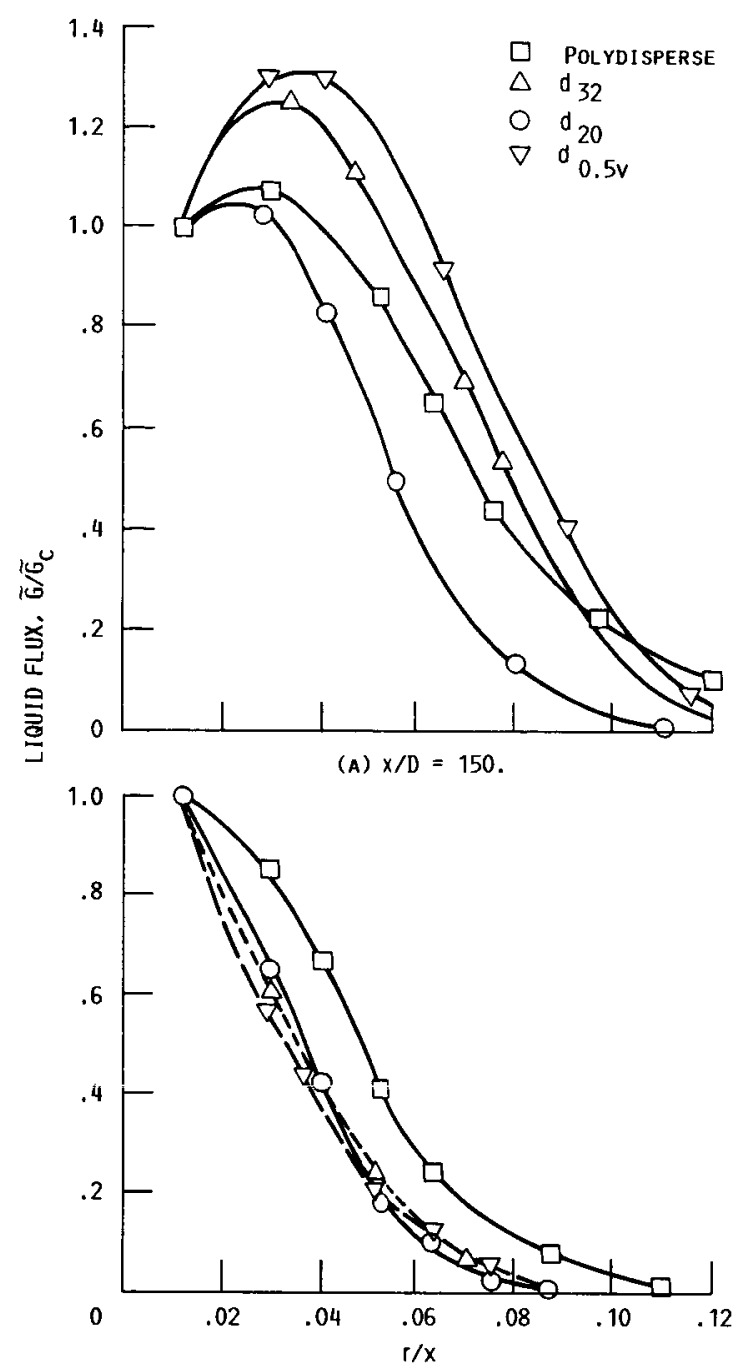

(B) $x / D=300$.

Figure 5. - Radial Variation of mean LIQUid methaNOL FLUX FOR THE POLYDISPERSE AND EOUIVALENT MONO-
DISPERSE SPRAYS.

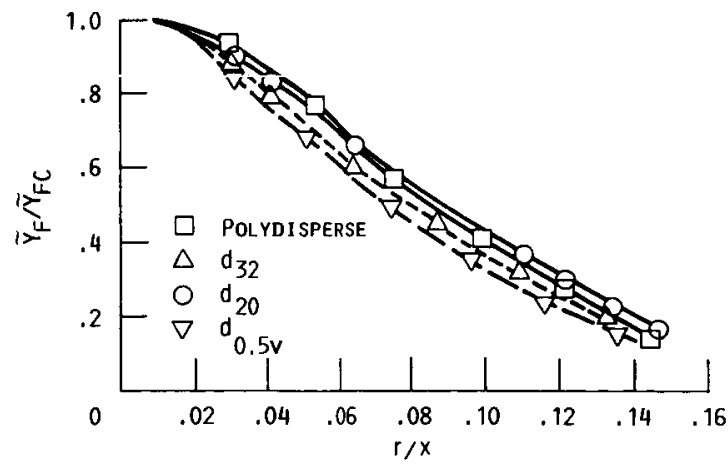

FIgURE 6. - RADial VARIATION OF TOTAL METHANOL MASS FRACT ION FOR THE POLYDISPERSE AND EQUIVALENT MONODISPERSE SPRAYS, $x / D=300$. 


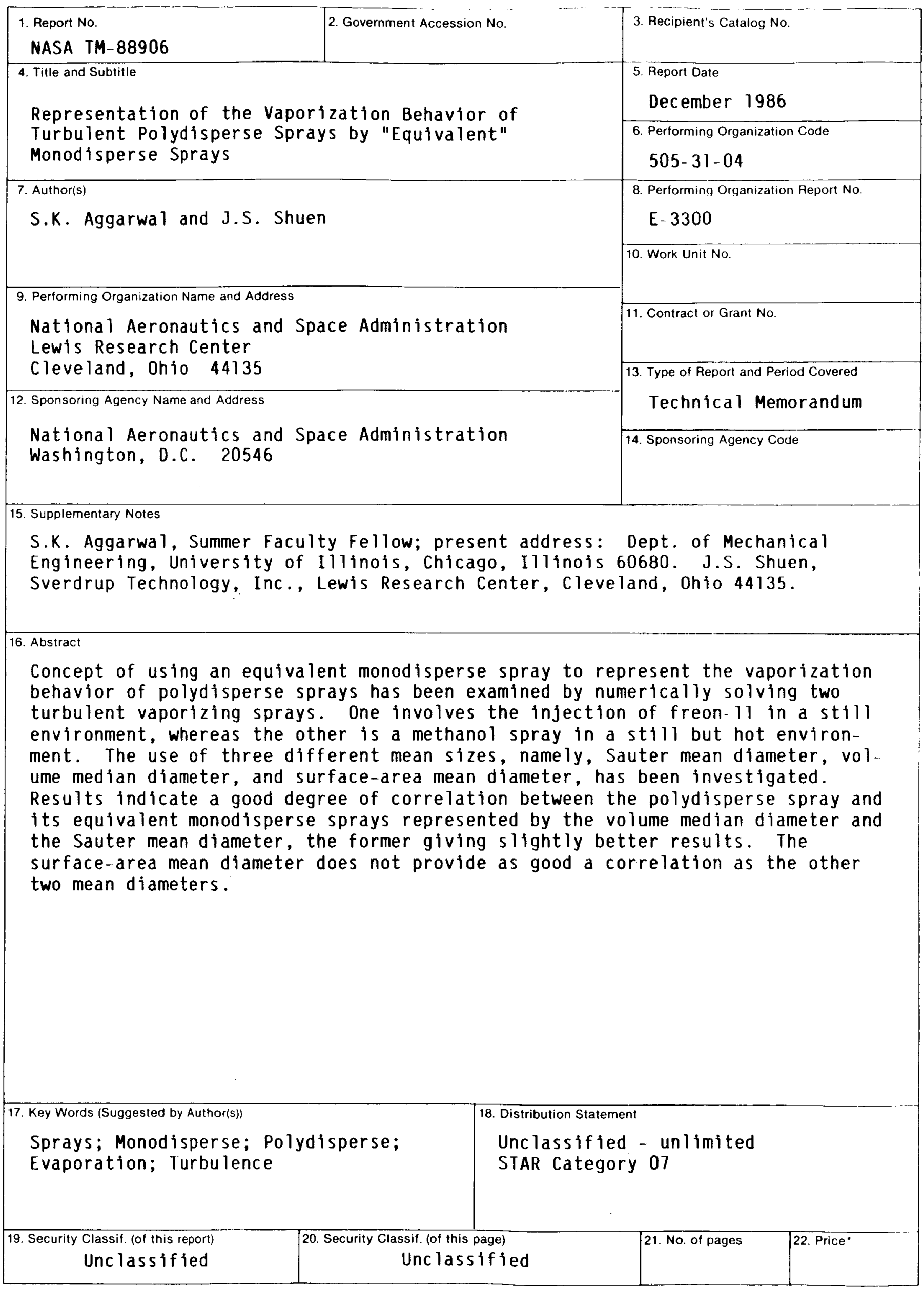

"For sale by the National Technical Information Service, Springfield, Virginia 22161 